\title{
Are the Children's Predispositions for Physical Exercise Influenced by Their Body Mass?
}

\author{
Václav Bunc*, Marie Skalská \\ Faculty of P.E. and Sports Charles University, Prague, Czech Republic \\ *Corresponding author: bunc@ftvs.cuni.cz
}

Received July 22, 2014; Revised September 10, 2014; Accepted September 18, 2014

\begin{abstract}
Poor nutrition, in addition to an overall lack of exercise, is one of the major issues of the current lifestyle. The most common consequence is the increase in overweight and obesity and decrease of physical fitness. The basic questions needed to be answered when designing exercise intervention: Are the physical assumptions affected by overweight or obese state? The exercise predispositions can be evaluated by the extracellular (ECM) and intracellular (BCM) mass ratio. To verify the dependence of the ECM/BCM on body mass (BM) we calculated $\mathrm{ECM} / \mathrm{BCM}$ for girls (normal BM, N=1598, mean age $=12.8 \pm 3.6 \mathrm{yrs}$, $\mathrm{BMI}=19.5 \pm 0.2 \mathrm{~kg} . \mathrm{m}^{-2}$; overweight, 178, $12.6 \pm 3.2,24.7 \pm 0.4$; obese, $219,12.9 \pm 3.4,29.6 \pm 0.6$ ), and in boys (normal $\mathrm{BM}, \mathrm{N}=1810$, mean age $=12.9 \pm 3.9 \mathrm{yrs}$, BMI $=19.9 \pm 0.3 \mathrm{~kg} . \mathrm{m}^{-2}$; overweight, 253, 1286 $\pm 3.2,24.9 \pm 0.4$; obese, 242, 12.9 \pm 3.4 , 30.3 \pm 0.6 ) differing in BM. We did not find significant differences in the ECM/BCM in girls and the same in boys, and non-significant dependence on BM. In conclusion: 1. the morphological predispositions for exercise are not dependent on BM, 2. do not exist any objective limitations for regular exercise realized in the children, 3 . for successful management of an overweight and/or obesity, it is necessary to influence both the diet and exercise.
\end{abstract}

Keywords: physical exercise, children, body composition, exercise predisposition, muscle morphology, bioimpedance

Cite This Article: Václav Bunc, and Marie Skalská, "Are the Children's Predispositions for Physical Exercise Influenced by Their Body Mass?” American Journal of Sports Science and Medicine, vol. 2, no. 5 (2014): 177-180. doi: 10.12691/ajssm-2-5-1.

\section{Introduction}

Poor nutrition, in addition to an overall lack of exercise, is one of the major issues of the current modern lifestyle. In addition to decreasing fitness, and the reduction of everyday working conditions as well as a drop in leisure activities, the most common end result is the increase in instances of obesity and, coincidentally, a population that is generally overweight $[1,2,3]$. The lack of daily realized physical activities results in significant decrease of physical fitness $[2,4,5,6]$. The energy content of current nutrition in majority western countries and of course in the Czech Republic too has been practically stable over the last two decades. The average daily energy intake of Czech children (both girls and boys) without regular physical exercise is about $120 \%$ of BMR [2]. In contrast, the energy content during general, daily function during the same period, decreased by about $30 \%$ [2]. The basis of regime interventions to influence obesity and actual fitness state is the increasing the daily volume of PA regularly carried out $[1,2,5,6]$.

Currently, begins in children due to the lack of movement regimen to decrease the level of the actual motor skills and thus reduce the supply of appropriate physical activities that are able to fill this gap. When designing an exercise intervention for improvement of this state should always respect previous movement experience, current physical fitness level and above mentioned current movement competence [2,4]. By the assessing the movement competence should be assessed together the skill requirements and the state of muscles that insuring specific physical activity [2].

For assessment of physical fitness and physical competence, may be advantageously used the body composition (BC) that reflects on the one hand the imposed physical load and thus the actual level of physical fitness on the one hand and on the other hand, muscle morphology $[7,8,9]$.

Age related changes in body composition (BC) have implications for physical function and health[10]. The redistribution and increase of fat and the loss of muscle mass result in substantial decrease in functional capacity. Although BC, as well as the age-related changes in it, has a strong genetic component, it is also influenced by environmental factors. The primary influences are nutrition, disease, and physical activity [8,9].

Clinically, BC is viewed in terms of two compartments: fat and fat-free mass [8,9,11]. Fat mass (FM) plus fat-free mass (FFM) that are make of proteins, water, and minerals, equals to the total body mass.

Beginning in middle adulthood, FFM begins to decline gradually both in men and women, primarily due to the wasting of muscle tissue [11,12,13]. Similarly like FFM decreases with age the body cell mass (BCM) in subjects 
without of systematically physical training. This similarity is confirmed by a high significant positive correlation between these both variables that was found in women [2]. The BCM is the sum of oxygen-using, calcium rich, glucose-oxidising cells. This variable may indirectly characterize the ability of human to sustain a mechanical work. Because the BCM is related to FFM and this to body mass it is for standardization often used the relationship ECM/BCM. Extracellular body mass (ECM) is defined like ECM = FFM - BCM $[7,8,9]$.
The age related changes in ECM/BCM relationship are presented on the Figure 1. The ECM/BCM values are in the age range of 20-60 years practically constant [2]. With the growing volume of musculoskeletal - movement load, the BCM volume increase at a significantly lower increase in ECM and therefore decreases the coefficient of ECM/BCM [2]. Generally it is true, that the lower the ECM/BCM coefficient, the better are preconditions for muscular work $[2,8,14]$.

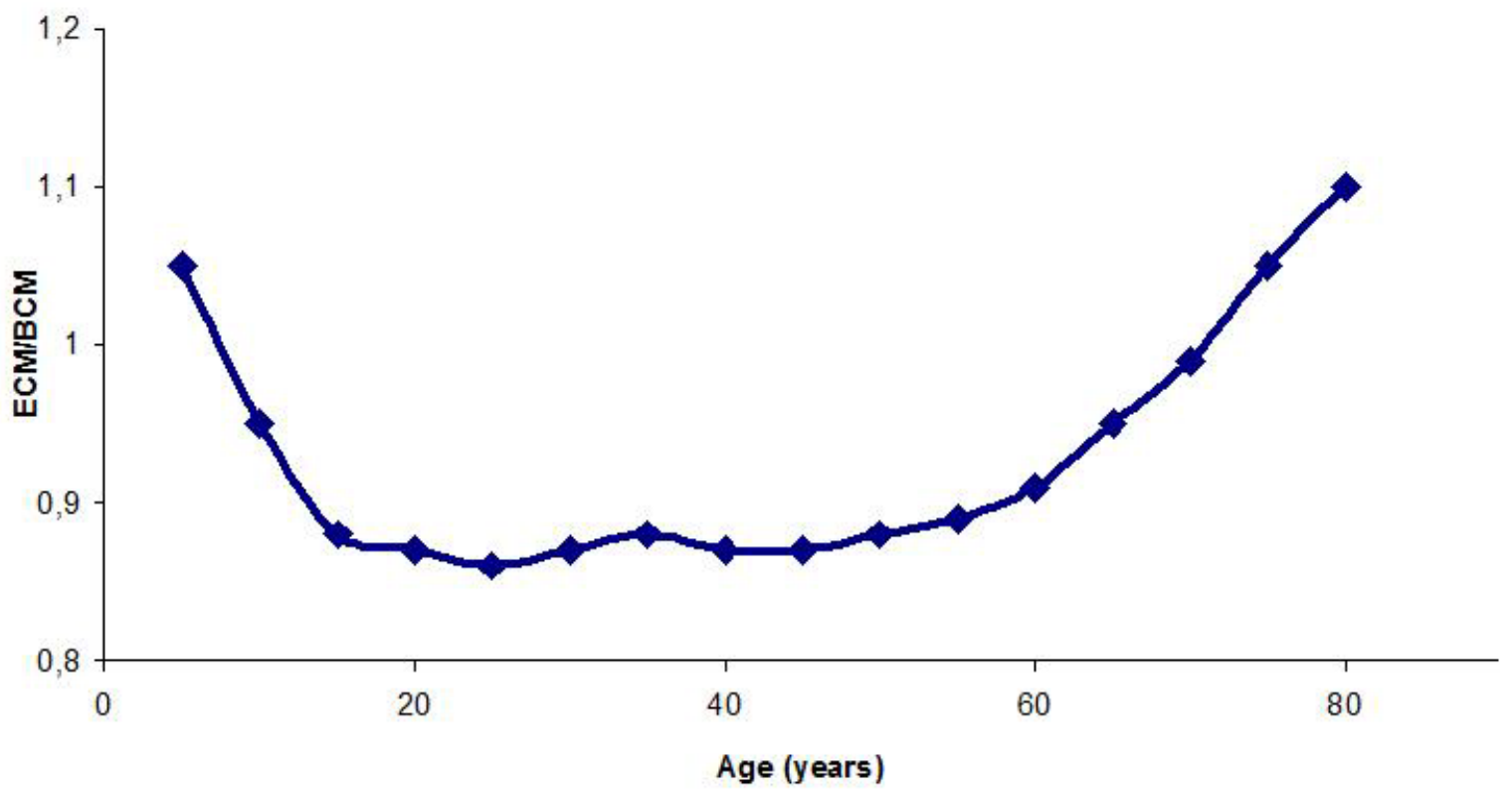

Figure 1. Dependence of the relationship ECM/BCM on the increasing age

Numerous tools and methodologies have been developed to measure various BC parameters. The bioelectrical impedance analysis (BIA) seems to be one of the most used methods in the field conditions $[8,9,12,14]$. Regardless of which instrument is chosen to assess BC, the method is only as good as the measurement technique and prediction or conversion formula applied. The conversion formulas and prediction equations selected use must be restricted to the populations from which they were derived to remain valid $[8,9,12,14]$.

The proportion between the ECM and BCM ratio may be used to identify fluid imbalance or malnutrition and/or to assess the predispositions for muscular work. The term malnutrition refers to the loss of structural body components, which is most accurately reflected by the BCM and an increase of the ECM $[8,9]$.

Lack of exercise regimen in people who are overweight or obese and/or or their current level of physical fitness is in sufficient is often explained by lower movement as sumptions for these people. It is true that many times these individuals have lower levels of motor skills as a result of completed mostly lower movement training, but an open question is whether they also have less muscle morphology, less quality of muscle mass, whether their muscle groups are less prepared to make the necessary physical activity $[1,2,5,15,16]$.

Thus the most common questions needed to be answered when designing exercise intervention are thus: are the physical assumptions for exercise affected by a body mass state?

\section{Methods}

\subsection{Ethical Aspects}

This study was approved by the Research Ethics Committee of Faculty of Physical Education and Sports Charles University.

\subsection{Subjects}

To verify the dependence of the coefficient ECM/BCM on body mass (BM) we used bioimpedance analysis; calculating this ratio for girls (normal $\mathrm{BM}, \mathrm{N}=1598$, mean age $=12.8 \pm 3.6 y r s, B M I=19.5 \pm 0.2 \mathrm{~kg} . \mathrm{m}^{-2}$; overweight, 178 ,

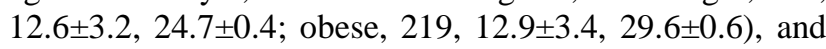
in boys (normal $\mathrm{BM}, \mathrm{N}=1810$, mean age $=12.9 \pm 3.9 \mathrm{yrs}$, $\mathrm{BMI}=19.9 \pm 0.3 \mathrm{~kg} \cdot \mathrm{m}^{-2}$; overweight, 253, 1286 \pm 3.2 , $24.9 \pm 0.4$; obese, $242,12.9 \pm 3.4,30.3 \pm 0.6$ ) differing in BM.

\subsection{Methods}

The division into groups- normal weight, overweight and obesity was based on BMI and body fat content according to data from Table 1.

To assess the predispositions for PA using body composition, we can look at the ratio of extracellular (ECM) and intracellular (BCM) mass. The size of this coefficient depends on age. In the range of 20-60 year olds is practically constant. The body cell mass is calculated using the FFM and phase angle between whole impedance 
vector and resistance $\alpha$ [2]. The extra cellular mass (ECM) is the difference between FFM and BCM - ECM = FFM BCM. The FFM was calculated according to modified formula of Deurenberg et al [12].

Table 1. Classification of body mass state according to BMI and \%BF in children of age ranged from 6 to 14 years

\begin{tabular}{|l|c|c|}
\hline Classification & $\begin{array}{c}\text { BMI } \\
\left(\mathrm{kg}^{-2}\right)\end{array}$ & $\begin{array}{c}\text { \%BF } \\
(\%)\end{array}$ \\
\hline Underweight & $<15.5$ & $<16.0$ \\
\hline Normal BM & $15.5-21.9$ & $16.1-23.0$ \\
\hline Overweight & $22.0-26.9$ & $23.1-28.0$ \\
\hline Obesity & $\geq 27$ & $\geq 28.1$ \\
\hline
\end{tabular}

Resistance and reactance were measured at four frequencies - 1, 5, 50 and $100 \mathrm{kHz}$ (B.I.A. 2000M, Data Input, Germany) on the right side of the body by tetrapolar electrode configuration in accordance with manufacturer's specification. For the calculation of body fat content were used the prediction equation that were valid in senior women by DEXA method.

The measurement itself was performed using the multifrequency BIA analyzer BIA $2000 \mathrm{M}$, in a tetrapolar configuration of electrodes on the right side of the body in a lying position. The arrangement of the electrodes followed the manufacturer's recommendations. The apparatus measures total impedance, i.e. allows determining its capacity and resistance components. In The hydration state was controlled 8 hours before the laboratory evaluation in all subjects.

\subsection{Statistical Analysis}

Means and standard deviations were calculated according to standard methods. The Pearson correlation was used for assessment of dependence in followed variables. The paired t-test was used to evaluate differences between means where appropriate. The level of statistical significance was set at $\mathrm{p}<0.01$.

The substantive significance is $1 \%$ in $\mathrm{BF} \%$, in coefficient ECM/BCM 0.03, and in BM, FFM, ECM and BCM $0.5 \mathrm{~kg}$.

\section{Results}

The mean values of \%BF and ECM/BCM coefficient are presented in Table 2. In all groups of children we find significant positive dependence of ECM/BCM on age $(p<0.01$ in all cases). For groups of the same gender, we did not find significant differences in the ECM/BCM and thus in predispositions for regularly exercise, and nonsignificant dependence on BM.

Table 2. Means and s of \%BF and ECM/BCM coefficient in followed groups of subjects differing in body mass (nbm - normal body mass, ow - overweight, ob - obese)

\begin{tabular}{|l|c|c|}
\hline & $\% B F(\%)$ & ECM/BCM \\
\hline Girls $_{\text {ob }}(\mathrm{n}=219)$ & $28.9 \pm 1.4$ & $0.90 \pm 0.02$ \\
\hline Girls $_{\text {ow }}(\mathrm{n}=178)$ & $24.6 \pm 1.2$ & $0.90 \pm 0.03$ \\
\hline Girls $_{\mathrm{nbm}}(\mathrm{n}=1598)$ & $19.6 \pm 1.7$ & $0.88 \pm 0.03$ \\
\hline Boys $_{\mathrm{ob}}(\mathrm{n}=242)$ & $29.5 \pm 1.6$ & $0.82 \pm 0.03$ \\
\hline Boys $_{\mathrm{ow}}(\mathrm{n}=253)$ & $23.8 \pm 1.3$ & $0.83 \pm 0.02$ \\
\hline Boys $_{\mathrm{nbm}}(\mathrm{n}=1810)$ & $20.3 \pm 1.5$ & $0.81 \pm 0.04$ \\
\hline
\end{tabular}

In girls we found the significant negative dependence of $\mathrm{ECM} / \mathrm{BCM}$ on age in the form

$$
\begin{aligned}
& \mathrm{ECM} / \mathrm{BCM}=-0.0213 * \text { age }(\text { years })+1.344 ; \mathrm{r}=0.891, \\
& \mathrm{p}<0.005, \mathrm{~S}_{\mathrm{EE}}=0.04, \mathrm{~T}_{\mathrm{EE}}=0.05
\end{aligned}
$$

In boys the relationship between ECM/BCM and age has a form

$\mathrm{ECM} / \mathrm{BCM}=-0.0265 *$ age $($ years $)+1.381 ; \mathrm{r}=0.873$,

$\mathrm{p}<0.005, \mathrm{~S}_{\mathrm{EE}}=0.04, \mathrm{~T}_{\mathrm{EE}}=0.05$.

\section{Discussion}

The basic findings of this study, we consider the fact that the coefficients of ECM/BCM and thus the preconditions for movement load are not dependent on body mass. Thus, the conditions for regular physical training for people without regular training are independent of body mass. They are of course significantly influenced absolved training and genetically $[2,7,11,17,18,19]$. In the subjects with the same or similar movement regime are predispositions for exercise independent of the total body mass. Therefore, lower the volume of the implemented training for people with higher body mass or obese is largely the result of lower movement regime, their convenience. Therefore, the foundation of all movement interventions that aim to adjust body mass or increase physical fitness is always leading to client's education to change their behavior, to change their lifestyle from sedentary to active.

The initially values of $\mathrm{BC}$ and aerobic fitness were slightly worse than are the Czech population standards of the similar age [2,7]. Unfortunately we have not comparable data about BCM and ECM of Czech adult population and/or other European countries. These data are lacking in to our known literature.

The using of ECM/BCM for evaluation of physical exercise predispositions was confirmed by the significant dependence of $\mathrm{VO}_{2 \max }$ on this variable. The relationship between $\mathrm{VO}_{2 \max }$ and physical performance was often presented in literature [e.g. 2,17]. In our group of girls $\left(\mathrm{N}=97\right.$, age $=13.4 \pm 3.4$ years, $\mathrm{VO}_{2 \max } \cdot \mathrm{kg}^{-1}=43.7 \pm 4.1$ $\left.\mathrm{ml} . \mathrm{kg}^{-1} \cdot \mathrm{min}^{-1}\right)$ and boys $(\mathrm{N}=128$, age $=13.1 \pm 3.2$ years, $\mathrm{VO}_{2 \mathrm{max}} \cdot \mathrm{kg}^{-1}=46.8 \pm 3.9 \mathrm{ml} \cdot \mathrm{kg}^{-1} \cdot \mathrm{min}^{-1}$ ) we found the significant dependence between $\mathrm{VO}_{2 \max } \cdot \mathrm{kg}^{-1}$ and $\mathrm{ECM} / \mathrm{BCM}$ (in girls $\mathrm{r}=0.796, \mathrm{p}<0.005$, and in boys $\mathrm{r}=0.781, \mathrm{p}<0.005$ ), and between ECM/BCM and physical performance (maximal speed of treadmill running) ( $\mathrm{r}=0.807, \mathrm{p}<0.005$ in girls andr=0.811, $\mathrm{p}<0.005$ in boys) [2]. Similar results dependence of $\mathrm{VO}_{2 \mathrm{max}} \cdot \mathrm{kg}^{-1}$ on ECM/BCM we found in adults females $(\mathrm{N}=84$, age $=43.1 \pm 3.8$ years, $\left.\mathrm{VO}_{2 \mathrm{max}} \cdot \mathrm{kg}^{-1}=32.4 \pm 4.1 \mathrm{ml} \cdot \mathrm{kg}^{-1} \cdot \mathrm{min}^{-1}\right) \quad(\mathrm{r}=0.812, \mathrm{p}<0.005)$, and on maximal speed of treadmill running $(\mathrm{r}=0.801$, $\mathrm{p}<0.005)$, and adult middle age men $(\mathrm{N}=67$, age $=44.8 \pm 3.4$ years, $\left.\quad \mathrm{VO}_{2 \max } \cdot \mathrm{kg}^{-1}=38.7 \pm 4.8 \mathrm{ml} \cdot \mathrm{kg}^{-1} \cdot \mathrm{min}^{-1}\right)$ we found similarly like in females of the same age the significant dependence between ECM/BCM and ( $r=0.796, \mathrm{p}<0.005)$, and between ECM/BCM and physical performance (maximal speed of treadmill running) ( $\mathrm{r}=0.807, \mathrm{p}<0.005)$.

The above presented dependence simply the possibility to use the coefficient of ECM/BCM like an important predictor for the expected exercise load. In practice this 
means that the coefficient of ECM/BCM can be used not only to assess the applied movement regime, but also for evaluating the effectiveness of the applied movement program. Changes in the ECM/BCM coefficient are the fastest response to qualitative hanges of the applied load locomotive. Significant changes we found already after about 7 days changed the training load [2,7].

The significant positive ECM/BCM dependence on age could be used for assessment of actual development state - biological age in subjects $[8,10,19]$. In actual case we compare real value of ECM/BCM with value that was calculated according to general relationship that is true for adult men.

In normal subjects of middle age, ECM/BCM ratios are recorded between 0.75 and 1.00, in seniors and in children these values may be higher than 1.10 [2,8,9,20,21]. Deviations from such figures toward higher values are due either to the erosion of BCM (catabolism) or to fluid expansion in extracellular spaces (edema). In the case of dehydration, we can observe the opposite phenomenon where the ECM/BCM ration is reduced.

With increasing volume of musculoskeletal load decreases the ratio ECM/BCM as a result of a growing amount of BCM. The default value is next to the completed locomotive load significantly genetically determined $[2,8,9]$.

\section{Conclusion}

In conclusion: 1 . the morphological predispositions for exercise are not dependent on BM in females without regular physical exercise, 2. there do not exist any objective limitations for regular PA realized in the majority of the children's population, 3. for successful management of an overweight populous and/or, in the case of individual obesity, it is necessary to influence both the energy intake (diet) and daily energy output (PA).

The study was supported by grant of Czech Ministry of Education MSM 00216208 and grant of Charles University Prague P38.

\section{References}

[1] Brettschneider, W.D., and R.Naul, “Obesity in Europe”. Frankfurt am Main: Peter Lang, 2007
[2] Bunc, V., "Walking as a tool of physical fitness and body composition influence”, Antropomotoryka, 57, 63-72, 2012.

[3] Haskell, W., et al., "Physical activity and public health: updated recommendation for adults from the American College of Sports Medicine and the American Heart Association”, Med Sci Sports Exercise, 39, 1423-1434, 2007.

[4] Blair, S.N. and J.C. Connelly, "How much physical activity should we do? The case for moderate amounts and intensities of physical activity”, RQES, 67(2), 193-205, 1996.

[5] Pate, R.R., and J.RO'Neill, J.R., "Summary of the American Heart Association Scientific statement: Promoting physical activity in children and youth: A leadership role for schools", JCardiovascular Nursing, 23(1), 44-49, 2008.

[6] Proper, K.I., et al., "The effectiveness of worksite physical activity programs on physical activity, physical fitness, and health”, Clin J Sport Med, 13(2): 106-117, 2003.

[7] Bunc, V. et al. "Body composition determination by whole body bioimpedance measurement in women seniors", ActaUniv Carol Kinathropologica, 36(1), 23-38, 2000.

[8] Heyward, V.H., and D.R. Wagner, "Applied body composition assessment”, Champaign: Human Kinetics, 2004.

[9] Roche, A.F., S.B.Heymsfield, and T.G.Lohman, "Human body composition”, Champaign: Human Kinetics, 1996.

[10] Karasik, D. et al., "Disentangling the genetic determinants of human aging: Biological age as an alternative to the use of survival measures”. J Geront, 60(5), 574-587, 2005.

[11] Blanchard, J., K.A.Conrad, and G.G. Harrison, "Comparison of methods for estimating body composition in young and elderly women”, J GerontBiolSci MedSci, 45, B119-B124, 1990.

[12] Deurenberg, P., and F.J.Schouten, "Loss of total body water and extracellular water assessed by multifrequency impedance”, Eur $J$ ClinNutr, 4: 247-55, 1992.

[13] Forbes, G.B., “The adult decline in lean body mass”, Hum Biol, 48: 161-173, 1976.

[14] Bunc, V., "Možnostistanovenítělesnéhosložení u dětíbioimpedančnímetodou (Possibilities of body composition determination in children using bioimpedance)", ČasLékčes, 146, 492-496, 2007.

[15] Karasik, D., et al. "Disentangling the genetic determinants of human aging: Biological age as an alternative to the use of survival measures”, J Geront, 60(5), 574-587, 2005.

[16] Katzmarzyk, P.T., et al. "International conference on physical activity and obesity in children: summary statement and recommendations", ApplPhysiolNutrMetab, 33(2), 371-388, 2008.

[17] Astrand, P.O., and K.Rodahl, "Textbook of Work Physiology", New York: McGraw Hill; 1986.

[18] Malina, R.M., and C.Bouchard, "Models and methods for studying body composition. Growth, maturation, and physical activity", Champaign: Human Kinetics, 1991.

[19] Spirduso, W.W., "Physical dimensions of aging”, Human Kinetics: Champaign, 1995.

[20] Bunc, V., et al., "Estimation of body composition by multifrequencybioimpedance measurement in children”, AnnNYAcadSci, 881, 203-204, 2000.

[21] Vandervoort, M., and A.J.McComas, "Contractile changes in oppositing muscles of the human ankle joint with aging”, $J$ ApplPhysiol, 61: 361-367, 1986. 